\title{
What Affects Mobile Application Use? The Roles of Consumption Values
}

\author{
Hsiu-Yu Wang ${ }^{1}$, Chechen Liao ${ }^{1}$ \& Ling-Hui Yang ${ }^{2}$ \\ ${ }^{1}$ Department of Information Management, National Chung Cheng University, Chia-Yi, Taiwan \\ ${ }^{2}$ Department of Food and Beverage Management, Tatung Institute of Commerce and Technology, Chia-Yi, \\ Taiwan \\ Correspondence: Hsiu-Yu Wang, Department of Information Management, National Chung Cheng University, \\ Chia-Yi, Taiwan. Tel: 886-2-272-4011. E-mail: Bonia.Wang@gmail.com
}

Received: January 21, 2013 Accepted: February 18, 2013 Online Published: February 28, 2013

doi:10.5539/ijms.v5n2p11 URL: http://dx.doi.org/10.5539/ijms.v5n2p11

\begin{abstract}
Today, mobile application (App) is a new emerging mobile technology and has been widely used. This new mobile artifact not only overturns the traditional business model of mobile industry, but also creates new avenues of mobile market opportunities. Although mobile pay-per-use services have attracted increased attention in recent years, few studies have provided limited insight into mobile technology adoption in pay-per-use services. In this study, we examine the determinants of behavioral intention of Apps users based on the theory of consumption values, and explore the roles of these values in mobile Apps context. Hypothesis testing was performed with structural equation modeling (SEM) on data collected from 282 mobile Apps users. The results reveal that consumption values significantly affect consumer behavioral intention to use mobile Apps. Among them, epistemic and motional values have stronger relationships with behavioral intention. Moreover, conditional value influences mobile App users' behavioral intention via the mediation of other consumption values (functional, social, emotional, and epistemic value). Finally, implications of the findings and areas for future research are discussed.
\end{abstract}

Keywords: consumption values, mobile application, perceived value, behavioral intention

\section{Introduction}

In 2007, the appearance of iPhone fired up the whirlwind of mobile application (App), and drove mobile application stores up and flourishing. Apple's App Store created new mobile value-added services (VAS), moreover, Apple boasts it as a new service type to meet the needs of mobile phone users-"whatever you want to do, there is an App for it" (Topology Research Institute: TRI, 2010). This new service type not only overturns the traditional business model of mobile industry, but also creates new avenues of mobile market opportunities. According to Gartner (2011) forecasting, worldwide mobile application store revenue is projected to surpass $\$ 15.1$ billion in 2011, both from end users buying applications and applications themselves generating advertising for their developers. Besides, by the end of 2014, Gartner (2011) also forecast over 185 billion applications will have been downloaded from mobile App stores since the launch of the first one in July 2008. Accordingly, Apps are being seen as a great opportunity of new revenue source in the mobile communication sector. While App has received wide attention, it is extremely important to understand the consumers' perception of Apps usage, especially for those parties who would like to get the profit from Apps.

Although mobile pay-per-use services have attracted increased attention in recent years, few studies have provided limited insight into mobile technology adoption in pay-per-use services. Referring to previous research, there are many theories or models applied to IS researches. The Theory of Reasoned Action (TRA) (Fishbein \& Ajzen, 1975), Theory of Planned Behavior (TPB) (Ajzen, 1991), Technology Acceptance Model (TAM) (Davis, Bagozzi, \& Warshaw, 1989) and Information Diffusion Theory (IDT) (Rogers, 1995). They are widely applied to investigate the adoption intention and usage behavior of IS users (Bruner, 2005; Hung, Ku, \& Chang, 2003 ; M. C. Lee, 2009). The validity and explanatory power of these models have been examined across many systems and contexts (King \& He, 2006), but in most contexts, models did not address the financial, social desirability, quality, emotional, and context-specific dimensions in a unified model (Turel, Serenko, \& Bontis, 2010). Much research in the marketing and IS domain show that perceived customer value is an important factor in users' 
decision processes in pay-per-user service behavior (H. W. Kim, Chan, \& Gupta, 2007; Turel, Serenko, \& Bontis, 2007). Moreover, consumer-behavior literature also shows that perceived value, which may be conceptualized before a product is bought or used, both strongly and stably predicts consumers' purchasing intentions (Eggert \& Ulaga, 2002; Sweeney \& Soutar, 2001). Thus, seeking the underlying motives or values that drives consumer to adopt, use and consume technology in general and mobile artifacts in particular (Blechar, Constantiou, \& Damsgaard, 2006).

This study applied the theory of consumption values developed by Sheth et al. (1991a) to investigate the key determinants of behavioral intention to employ pay-per-use mobile artifacts, especially for Apps. The consumption values include functional, social, emotional, epistemic and conditional values. Most of the earlier value-based studies employed Sweeney and Souter's (1999) PERVAL as the theoretical foundation, and excluded the epistemic and conditional values from their investigations (Deng, Lu, Wei, \& Zhang, 2010; Y. Lee, Kim, Lee, \& Kim, 2002; Turel et al., 2007; Yang \& Jolly, 2009), only rare researchers employed these two values as factors in their researches (Pihlstrom \& Brush, 2008; Pura, 2005). Nevertheless, Braiterman and Savio (2007) indicated that "context is everything" in mobile interaction, condition-specific value dimension cannot be ignored in value-based investigation. Therefore, two research questions are investigated in this study. First, we examine the key value components to drive mobile users' behavioral intentions to use Apps. The next, we explore the roles of consumption value in the mobile Apps context.

The remainder of the paper is organized as follows. The next section discusses the theoretical background of value. The subsequent section develops a framework of value structure and presents the research hypotheses. The method is described next and the results follow. The paper ends with a discussion of the results, contributions for research and practice, and suggestions for future research.

\section{Theoretical Background and Hypotheses}

\subsection{Mobile Application}

A mobile application (or mobile App) is software application that runs on a mobile device (smart phone, tablet, iPod, etc.), and has an operating system that supports standalone software (Wikipedia, 2012). They are available through application distribution platforms, which are typically operated by the owner of the mobile operating system, such as the Apple App Store, Google Play, Windows Phone Store and BlackBerry App World (Siegler, 2008). Mobile Apps can come preloaded on the mobile device as well as can be downloaded by users from mobile App stores or the Internet. Moreover, mobile Apps usually help users by connecting them to Internet services more commonly accessed on desktop or notebook computer, or help them by making it easier to use the Internet on their portable devices.

\subsection{The Concept of Perceived Value}

Value is considered to be an important constituent of relationship marketing and the ability of a company to provide superior value to its customers is regarded as one of the most successful strategies for the 1990s. This ability has become a mean of differentiation and a key to the riddle of how to find a sustainable competitive advantage (Ravald \& Grönroos, 1996). In addition, Holbrook (1994) addressed that "Marketing involves exchanges; exchanges depend on customer value; therefore, customer value is the fundamental basis for all marketing activity". Customer perceived value, a strategic imperative for producers and retailers in the 1990s, will be of continuing importance into the twenty-first century (Sweeney \& Soutar, 2001; Woodruff, 1997). Consumers purchase not only based on the superior economic or utility value that they obtain, but increasingly because of the perceived corporate, social and environmental reputation value of the firm purveying the product, brand or service (Tarn, 1999). Therefore, if consumers are really "value-driven" (Sweeney \& Soutar, 2001), then practitioners need to understand what customer perceived value and where they should focus their attention to achieve this needed market place advantage (Woodruff, 1997).

While customer perceived value has been defined and adapted by a number of different researchers, there are two approaches are applied: uni-dimensional and multi-dimensional approaches. The perspective of uni-dimensional approach consider perceived value to be a cognitive trade-off between benefits and sacrifices (Monroe, 1990). However, in a marketing context, perceived value is not just limited to the functional aspects of quality and price, but may also include other components (Sheth et al., 1991a). The multi-dimensional construct that consists of several interrelated attributes or dimensions that form a holistic representation of a complex phenomenon. It means perceived value is a variety of notions (such as perceived price, quality, benefits, and sacrifice) are all embedded (Babin, Darden, \& Griffin, 1994; Holbrook, 1994; Sheth, Newman, \& Gross, 1991b; Sweeney \& Soutar, 2001; Woodruff, 1997). Sheth et al. (1991b) argued that consumer purchase choice entails a variety of forms of value. These forms of value can be categorized as functional, social, emotional, epistemic, 
and conditional. In addition, Babin et al. (1994) addressed that assessed consumers' evaluations of a purchase experience along two dimensions: hedonic and utilitarian values.

As prior researchers (e.g. H. W. Kim et al., 2007; Turel et al., 2007) mentioned, the users of information and communication technology (ICT) are not only technology users, but also the service consumers. To understand the behaviors of ICT users can not only considers the technology utilities, but also take other factors into account, such as emotional, psychological, or social factors. Moreover, both the marketing and the IS disciplines have empirically proved that perceived value is multi-dimensional and can be measured by a variety of instruments (e.g. Pura, 2005; Sweeney \& Soutar, 2001). Particularly in mobile technology and service contexts, numerous empirical studies have applied perceived value concept to investigate the mobile technologies adoptions and usage, such as mobile internet (e.g. H. W. Kim et al., 2007), location-based services (e.g. Pura, 2005), or mobile data services (e.g. B. Kim \& Han, 2009; Yang \& Jolly, 2009), and find the significant influences of perceived value on customers' adoption or usage behaviors. Consequently, this study utilized the multi-dimensional value approach to investigate the antecedents and consequences of mobile Apps use.

\subsection{Hypotheses Development}

Among these approaches to perceived value, Sheth et al. (1991a) is one of the most important contributions to the study of perceived value in that the authors define a complex multi-dimensional structure for the concept (Sanchez-Fernandez \& Iniesta-Bonillo, 2007). We therefore employ the theory of consumption values to explain the behavioral intention of Apps use. This theory integrates components from various consumer behavior models and assumes that consumer choice is a function of multiple consumption values (Turel et al., 2010); the importance of this theory lies in positing that consumers balance value assessments for making informed, intrinsically and extrinsically motivated consumption decision (H. W. Kim et al., 2007). Sheth et al. (1991b) argued that a customer purchase choice was influenced by a multiple consumption value dimension (functional, emotional, social, epistemic, and conditional value), and different dimensions have different roles in the user's decision (Deng et al., 2010). Thus, the TCV is more applicable to explain individual consumption behavior. In the present study, we propose the framework of a value structure composed of different types of values for exploring the behavioral intention to use Apps by using the theory of consumption values. The research model is established as shown in Figure 1.

\subsubsection{Functional Value}

Functional value concerns the utilitarian functions and services that a product can offer. The value is often manifested through a product's composite attributes such as qualities or features that can deliver impressions of utilitarian performance(Tzeng, 2011). According to Sheth et al. (1991a), functional value pertains to the ability of product to perform its functional, utilitarian, or physical purpose and while it may be based on any salient physical attribute, sometimes price is the most salient functional value. In IS and mobile service contexts, functional value have empirically proven that positively affect users' behavioral intentions to use information systems (e.g. Cheng, Wang, Lin, \& Vivek, 2009; Tzeng, 2011), or mobile services (e.g. Pura, 2005; Turel et al., 2007; Yang \& Jolly, 2009). Mobile App is a new ICT artifact. Mobile App is an information software, and can provide mobile service to satisfy mobile users' needs. Hence, the function value of mobile App is expected to positively influence users' behavioral intention to use mobile Apps. The hypothesis is also proposed.

H1. Functional value positively affects the behavioral intention to use mobile Apps.

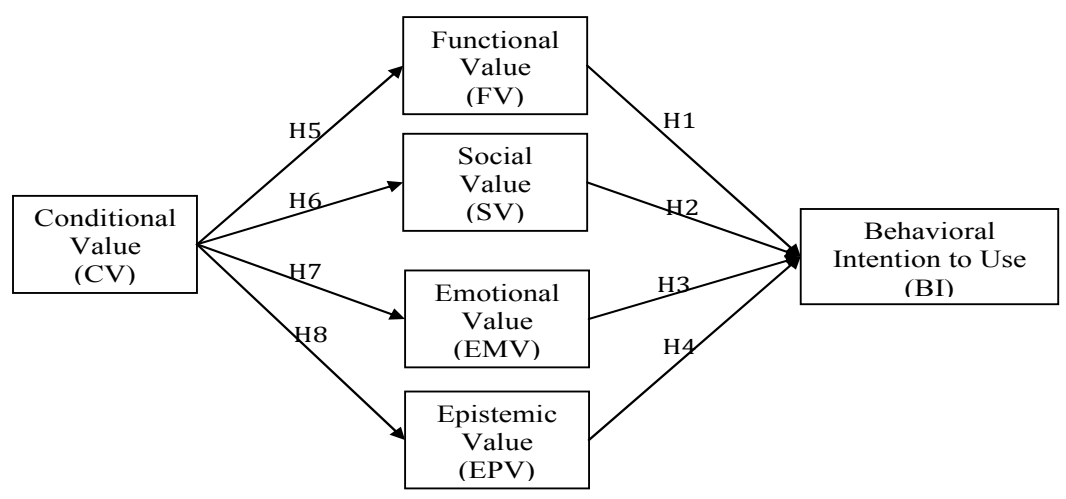

Figure 1. Research model 


\subsubsection{Social Value}

Social value (SV) has been defined as the "perceived utility acquired from an alternative's association with one or more specific social groups" (Sheth et al., 1991a). Choices involving highly visible products (e.g. clothing, jewelry) and goods or services shared with others (e.g. gifts, products used in entertaining) are often driven by social value (Sheth et al., 1991a). Hence, social value relates to social approval and the enhancement of self-image among other individuals (Sweeney \& Soutar, 2001). The motive of buying and using products depends on how a consumer wants to be seen by others and/or how he wants to see himself (Sheth et al., 1991a; Sweeney \& Soutar, 2001). The purchase and use of products is a means by which an individual can express self-image socially to others. Within present context, it is obvious that the App is considered to represent a modern product and is getting more and more attention. Hence, using Apps is now considered to be fashionable, people using Apps therefore can promote his/her self-image. Both in IS and service context, much previous research has well demonstrated that social value will positively affect the behavioral intention to use or purchase the IS artifacts or mobile services (e.g. Chen, Shang, \& Lin, 2009; Cheng et al., 2009; Hsu \& Chen, 2007; Yang \& Jolly, 2009). We hence define social value as the utility of mobile App derived from its perceived ability to enhance social well-being, and we make the following hypothesis:

H2. Social value positively affects the behavioral intention to use mobile Apps.

\subsubsection{Emotional Value}

Emotional value (EMV) is a social-psychological dimension that is dependent on a product's ability to arouse feelings or affective states (Sheth et al., 1991b). A product acquires emotional value when associated with specific feelings or when precipitating or perpetuating those feelings. Play or fun gained by using a product/service for its own sake is related also to emotional value (Holbrook \& Hirschman, 1982). In this study, the emotional value reflects enjoyment, playfulness, fun, and pleasure of using mobile Apps. It has been argued that emotional components, such as enjoyment and playfulness, could promote the use of information systems, respectively (Tseng, 2011; Verkasalo, López-Nicolás, Molina-Castillo, \& Bouwman, 2010). It has also been demonstrated that the emotional value is an important impact factor to influence the usage intention in mobile service context (e.g. H. W. Kim et al., 2007; Mallat, Rossi, Tuunainen, \& Oorni, 2009; Turel et al., 2010). Therefore, it seems that users who find the mobile Apps enjoyable and emotionally fulfilling to use are more likely to have a higher use intention. Thus, we make the following hypothesis:

H3. Emotional value positively affects the behavioral intention to use mobile Apps.

\subsubsection{Epistemic Value}

Epistemic value (EPV) is created when a product/service arouses curiosity, provides novelty and/or satisfies a desire for knowledge (Sheth et al., 1991a). In some contexts, it could refer to novelty value and the value from learning new ways of doing things. For example, in a mobile context, it entails curiosity for new content and knowledge gained through testing new services (Pihlstrom \& Brush, 2008). Also, in the IS context, the adoption of online games may be triggered by the desire to satisfy one's curiosity or experience the novelty of the new technology (Okazaki, 2008). Additionally, previous research have shown that epistemic value can influence customer's purchase or usage intention in IS or mobile context (e.g. Cheng et al., 2009; Pura, 2005; Tzeng, 2011). Mobile App is an innovative product of ICT, a software, and a service in mobile context. It provides user interface for basic telephony and message services, as well as for advantage services such games and videos. Therefore, the effect of epistemic value on the behavioral intention of Apps use can clearly arise from curiosity and novelty as well as from the knowledge-seeking viewpoint. Thus, we make the following hypothesis:

H4. Epistemic value positively affects the behavioral intention to use mobile Apps.

\subsubsection{Conditional Value}

Sheth et al. (1991a) described conditional value (CV) as the perceived utility acquired by an alternative as the result of the specific situation or set of circumstances facing the choice maker. Furthermore, Holbrook (1994) presumes that conditional value depends on the context in which the value judgment occurs and exits only within a specific context. Thus, conditional value applies to products or services whose value is strongly tied to use in a specific context. It might be derived from temporary functional or social value (Sheth et al., 1991a), hence it arises when the circumstances create a need. For example, a winter coat may have significant value during a winter snowstorm, but no value during a hot summer day. Thus, conditional value could be described as a specific case of other types of value (Sweeney \& Soutar, 2001). As Balasubramanian et al. (2002) state, that mobile technologies are especially useful in situations where time and space are critical. App is a new emerging mobile product; it can also offer many kinds of service for customers in specific situations. For example, mobile 
users can use the Apps with GPS functions to identify their current location and find the correct direction of destination after becoming lost. Besides, mobile users can know the bus arrival time by using an App when they are waiting for the bus at a bus station. The studies, in mobile context, to test the relationships between conditional value and other value dimensions (e.g. Gummerus \& Pihlström, 2011; Pihlstrom \& Brush, 2008), showed that conditional value has the significant relationships with all value categories. Again, in IS context, Tzeng (2011) evidenced that contextual value influences user's intention to use a career e-portfolio system via the mediation of functional value as well. Thus, in this study, conditional value is expected to have a positive relationship with other value dimensions. The hypotheses are made as follows:

H5. Conditional value is positively related to functional value.

H6. Conditional value is positively related to social value value.

H7. Conditional value is positively related to emotional value.

H8. Conditional value is positively related to epistemic value.

\section{Research Method}

\subsection{Instrument Development}

A questionnaire survey was used to collect data on mobile device users' perception of Apps. Most of the instruments used to measure the constructs in this study are adapted from previous studies in order to ensure content validity. Items measuring consumption values, including functional, emotional and social value are adapted from Pura (2005) and Sweeney and Soutar (2001). Epistemic value is measured by items adapted from Pihlström and Brush (2008). Moreover, referring to the findings of Gummerus and Pihlström (2011) exploring study, it is indicated that conditional value of using mobile technologies is effected from four aspects: time, location, access and uncertain condition. Therefore, we created the measurement items of conditional value according to the exploring study results of Gummerus and Pihlström (2011). Behavioral intention is measured by items adapted from Yang and Jolly (2009). After we developed the preliminary questionnaire, a series of pilot studies were conducted to ensure consistency and soundness of measurements of value structures and eliminate similar wording and logically duplicative items. The initial questions were pilot testes in an internet survey with 60 mobile phone users who had experienced Apps and downloaded Apps more than once in Taiwan. Based on the results of the pilot studies, 24 questions are used for the main survey. Detailed information about the constructs and the sources are presented in Appendix A. All the items are measured on seven-point Likert scales, with anchors ranging from "strongly disagree" to "strongly agree".

\subsection{Data Collection Procedure}

The data were collected through an internet survey conducted. We posted the information about our research objective and the website address of our questionnaire on some social network sites (e.g. Facebook, Mobile01) and Campus BBS (Bulletin Board System) to invite respondents. We also sent this information to many individual email addresses to invite them to join. After eliminating inconsistence and incomplete responses through data filtering, we got a total number of 282 usable responses.

The descriptive statistics of the sample are shown in Table 1 . Of the 282 effective respondents, $56 \%$ are the male and $44 \%$ are the female, and 152 are below 25 years old. Among 282 respondents, about 54\% of them have used Apps for more than 1 year, and around 67\% of them have not spent any money on Apps download in the past 6 months. The demographic distribution reveals a diverse sample, comprising a wide range of age, with approximately an equal representation of gender and usage experience. 
Table 1. Demography information of respondents $(n=282)$

\begin{tabular}{llll}
\hline Measure & Items & Frequency & Percent \\
\hline Gender & Male & 158 & 56.0 \\
& Female & 124 & 44.0 \\
\hline Age & $<18$ & 4 & 1.4 \\
& $18-24$ & 148 & 52.5 \\
& $25-34$ & 59 & 20.9 \\
& $35-44$ & 53 & 18.8 \\
& $45-54$ & 18 & 6.4 \\
\hline Occupation & Student & 133 & 47.2 \\
& Government & 14 & 5.0 \\
& IT & 47 & 16.7 \\
& Service & 24 & 8.5 \\
& Medicine & 4 & 1.4 \\
& Manufacture & 30 & 10.6 \\
& Financial/Insurance & 18 & 6.4 \\
& Transport & 2 & 0.7 \\
& Farming & 1 & 0.4 \\
& Housewife & 2 & 0.7 \\
& Waiting for job & 5 & 1.8 \\
& Others & 2 & 0.7 \\
\hline Years using Apps & $<0.5$ year & 65 & 23.0 \\
& $0.5-1.0$ year & 65 & 23.0 \\
& $1.0-2.0$ years & 80 & 28.4 \\
& $2.0-3.0$ years & 52 & 18.4 \\
& $3.0-4.0$ years & 7 & 2.5 \\
Fees using Apps & 4 years or more & 13 & 4.6 \\
(NTD/Monthly) & 0 & 188 & 66.7 \\
$(1$ USD $\fallingdotseq 29$ NTD) & $1-100$ & 59 & 20.0 \\
& $101-200$ & 19 & 6.7 \\
& $201-300$ & 6 & 2.1 \\
& $301-500$ & 3 & 1.1 \\
& 501 or more & 7 & 2.5 \\
\hline
\end{tabular}

\section{Analysis and Results}

Data analysis utilized a two-step approach as recommended by Anderson and Gerbing (1988). The first step involves the analysis of the measurement model, while the second step tests the structural relationships among latent constructs. SmartPLS 2.0M3 was used to assess both the measurement model and the structural model, because partial least squares (PLS) places minimal restrictions on the measurement scales, sample size and residual distribution (Chin \& Newsted, 1999).

\subsection{Measurement Model}

Reliability is examined using the composite reliability values. Table 2 shows that all the values are greater than 0.9, which satisfying the commonly acceptable level (Bagozzi \& Yi, 1988). Convergent validity is demonstrated as the AVE values for all constructs were above the suggested threshold value of 0.50 (Fornell \& Larcker, 1981) (Table 2), and all indicator loadings above 0.70 on their respective construct.

Discriminant validity was tested using the following two tests. First, an examination of cross-factor loadings (Table 3) indicates good discriminant validity, because the loading of each measurement item on its assigned latent variable is larger than its loading on any other constructs (Chin, 1998). Second, the square root of the AVE from the construct is much larger than the correlation shared between the construct and other constructs in the model (Table 4) (Fornell \& Larcker, 1981). Thus, the discriminant validity was satisfied in all cases. 
Table 2. Descriptive statistics for the constructs

\begin{tabular}{llll}
\hline Constructs & AVE & Composite Reliability & Cronbach's Alpha \\
\hline Behavioral Intention (BI) & 0.7704 & 0.9305 & 0.9001 \\
Functional Value (FV) & 0.6602 & 0.9063 & 0.8699 \\
Social Value (SV) & 0.8350 & 0.9529 & 0.9340 \\
Emotional Value (EMV) & 0.7550 & 0.9389 & 0.9181 \\
Epistemic Value (EPV) & 0.7816 & 0.9148 & 0.8605 \\
Conditional Value (CV) & 0.7688 & 0.9088 & 0.8494 \\
\hline
\end{tabular}

Table 3. Matrix of loadings and cross-loadings

\begin{tabular}{lllllll}
\hline & BI & CV & EMV & EPV & FV & SV \\
\hline BI1 & $\mathbf{0 . 9 1 1 3}$ & 0.5407 & 0.5915 & 0.6072 & 0.4678 & 0.3309 \\
BI2 & $\mathbf{0 . 9 2 6 7}$ & 0.5816 & 0.6412 & 0.6200 & 0.5398 & 0.3525 \\
BI3 & $\mathbf{0 . 8 3 5 6}$ & 0.4459 & 0.4876 & 0.4829 & 0.4525 & 0.3552 \\
BI4 & $\mathbf{0 . 8 3 3 0}$ & 0.4742 & 0.4781 & 0.5176 & 0.4400 & 0.4563 \\
CV1 & 0.4996 & $\mathbf{0 . 8 5 4 8}$ & 0.5176 & 0.5095 & 0.4342 & 0.2509 \\
CV2 & 0.4999 & $\mathbf{0 . 8 6 9 6}$ & 0.4511 & 0.5238 & 0.3784 & 0.2810 \\
CV3 & 0.5393 & $\mathbf{0 . 9 0 5 3}$ & 0.4929 & 0.5782 & 0.4465 & 0.2925 \\
EMV1 & 0.5575 & 0.5517 & $\mathbf{0 . 8 6 3 3}$ & 0.5465 & 0.6365 & 0.3681 \\
EMV2 & 0.5190 & 0.5022 & $\mathbf{0 . 8 8 7 5}$ & 0.4950 & 0.6487 & 0.3845 \\
EMV3 & 0.5232 & 0.4312 & $\mathbf{0 . 9 0 2 2}$ & 0.4732 & 0.5524 & 0.3584 \\
EMV4 & 0.6017 & 0.5064 & $\mathbf{0 . 9 0 5 9}$ & 0.5412 & 0.6011 & 0.3531 \\
EMV5 & 0.5337 & 0.4093 & $\mathbf{0 . 7 7 9 3}$ & 0.4699 & 0.4948 & 0.3733 \\
EPV1 & 0.5458 & 0.5060 & 0.4403 & $\mathbf{0 . 8 7 1 4}$ & 0.4073 & 0.4067 \\
EPV2 & 0.5490 & 0.5299 & 0.4914 & $\mathbf{0 . 8 9 0 5}$ & 0.4664 & 0.4037 \\
EPV3 & 0.5958 & 0.5865 & 0.6067 & $\mathbf{0 . 8 9 0 3}$ & 0.4566 & 0.3419 \\
FV1 & 0.4147 & 0.3978 & 0.5221 & 0.3699 & $\mathbf{0 . 8 4 7 0}$ & 0.2494 \\
FV2 & 0.4377 & 0.3693 & 0.5096 & 0.4279 & $\mathbf{0 . 8 6 2 2}$ & 0.3197 \\
FV3 & 0.4186 & 0.3558 & 0.5223 & 0.3985 & $\mathbf{0 . 8 5 4 5}$ & 0.3434 \\
FV4 & 0.5087 & 0.4496 & 0.6317 & 0.4710 & $\mathbf{0 . 7 6 5 5}$ & 0.3207 \\
FV5 & 0.4027 & 0.3551 & 0.5439 & 0.3503 & $\mathbf{0 . 7 2 3 9}$ & 0.2622 \\
SV1 & 0.3897 & 0.3134 & 0.3963 & 0.4221 & 0.3178 & $\mathbf{0 . 8 8 4 6}$ \\
SV2 & 0.3928 & 0.2617 & 0.3849 & 0.3820 & 0.3116 & $\mathbf{0 . 9 3 6 3}$ \\
SV3 & 0.3889 & 0.3189 & 0.3944 & 0.4056 & 0.3673 & $\mathbf{0 . 9 3 4 7}$ \\
SV4 & 0.3692 & 0.2455 & 0.3665 & 0.3675 & 0.3575 & $\mathbf{0 . 8 9 8 6}$ \\
\hline
\end{tabular}

Table 4. Correlation matrix (diagonal represents square root of AVE values)

\begin{tabular}{lllllll}
\hline & BI & CV & EMV & EPV & FV & SV \\
\hline BI & $\mathbf{0 . 8 7 7 7}$ & & & & & \\
CV & 0.5855 & $\mathbf{0 . 8 7 6 8}$ & & & & \\
EMV & 0.6313 & 0.5562 & $\mathbf{0 . 8 6 8 9}$ & & & \\
EPV & 0.6385 & 0.6134 & 0.5838 & $\mathbf{0 . 8 8 4 1}$ & & \\
FV & 0.5430 & 0.4798 & 0.6783 & 0.5022 & $\mathbf{0 . 8 1 2 5}$ & \\
SV & 0.4219 & 0.3135 & 0.4226 & 0.4326 & 0.3704 & $\mathbf{0 . 9 1 3 8}$ \\
\hline
\end{tabular}

\subsection{Structural Model}

Path coefficients and R-square values were obtained by running the PLS algorithm to assess the predictive performance of the structural model. The significance of research model was assessed with 500 bootstrap runs. Figure 2 shows the results of structural path analysis. All paths exhibited the P-values more than 0.05 . Overall, the base model accounted for $53 \%$ of the variance of behavioral intention. Thus, the fit of the overall model is good. 


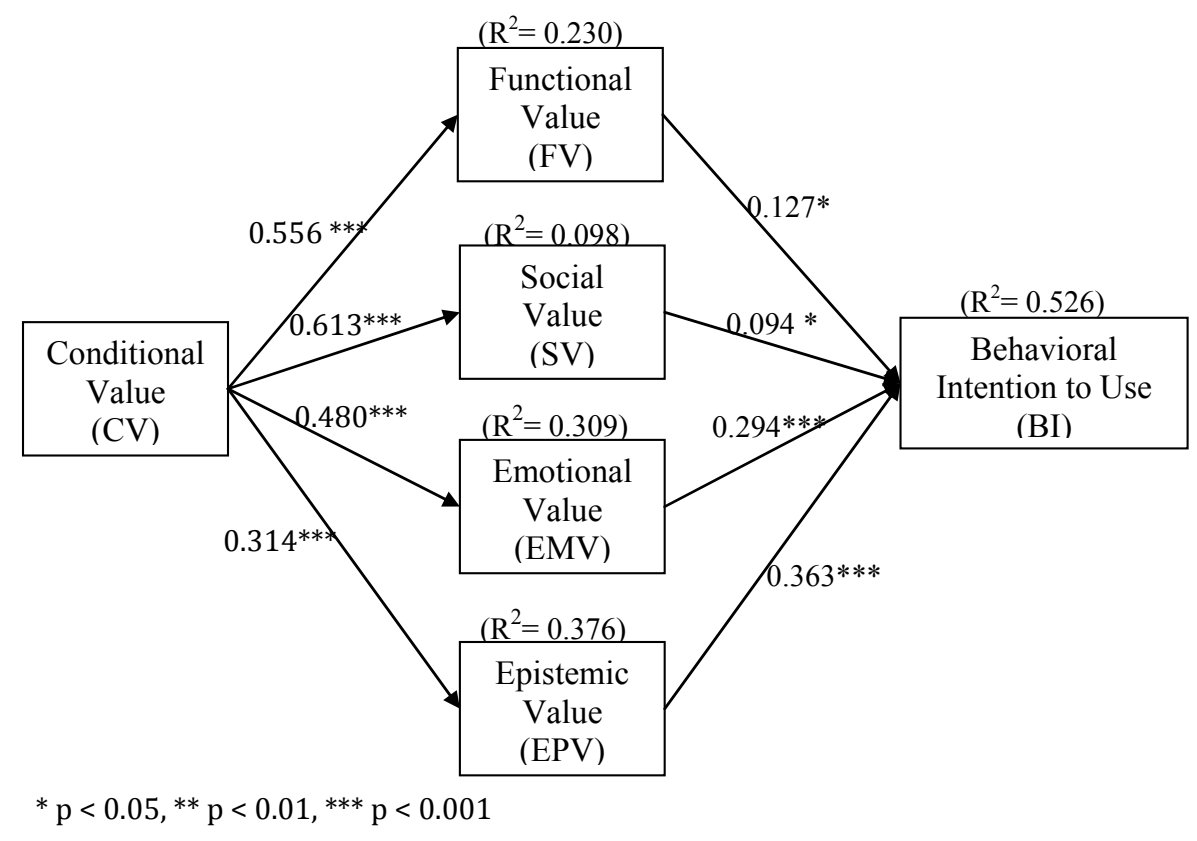

Figure 2. Results of the PLS analysis

\section{Discussion and Implications}

As hypothesized, the results of the current study confirm that functional, social, emotional, and epistemic values have significant effects on behavioral intention to use mobile Apps. Among these values, the influences of emotional and epistemic values are stronger than functional and social values. According to Apple App store, the type of most of App downloads is game. Consumers used this type App might result from their curiosity, when they experienced the new games, their emotional needs can be satisfied by the pleasure or fun, and hence the functions and social approval are hence less important.

In sum, this study attempted to explore the factors affecting consumers behavioral intentions to use mobile Apps, especially examined the effects of conditional value in mobile Apps context. We considered mobile technology use as consumption to research the roles of consumption values on behavioral intention in mobile Apps context. This paper demonstrates conditional value significantly affect mobile App users' behavioral intentions via the mediation of functional, social, emotional, and epistemic value. This finding indicates that context factor should be considered in mobile technology use, and responds to earlier researcher's arguments (e.g. Gummerus \& Pihlström, 2011; Sweeney et al., 1999) that contextual factors cannot be disregarded in ICT use research.

\subsection{Implications for Research}

In terms of research contribution, this study improves on prior research effort to understand consumer behavior regarding mobile technology. First, by studying users' responses from a consumption-value based perspective, this paper helps predict and explain a wide range of ICT-related usage behaviors. The paper shows that utilitarian and hedonic experiences by using a new mobile technology can have important subsequent implications for users.

Second, this study contributes to the value literature by proposing and testing the roles of consumption values on behavioral intention in mobile App context. Referring to earlier value-based studies, most of the studies employed PERVAL (Sweeney \& Soutar, 2001) as the theoretical foundation, and excluded the epistemic and conditional value dimensions from their investigations (Deng et al., 2010; Turel et al., 2007; Yang \& Jolly, 2009). Only rare researchers employed these two values as factors in their researches (Pihlstrom \& Brush, 2008; Tzeng, 2011). While some authors even suggested that in mobile interactions "context is everything" (Braiterman \& Savio, 2007), our results empirically evidenced that contextual factor was an important factor affecting mobile technology use. This finding demonstrates that consumption values are not absolutely independent in mobile technology context, the correlations between consumption values might probably be changed. 


\subsection{Implications for Practice}

The results of the current study give two implications for App developers and marketing managers with regard to how to plan and market Apps that will be considered valuable by consumers and used in future. First, technology is used to improve the quality of human life, whether in substance or spirit. Similarly, the purpose of the development of mobile technology is to enhance and enrich consumers' lives and satisfy their needs. Such as a Nokia slogan-“Connecting People"-says, by engaging in customers' situated contexts, Apps and mobile marketing can surpass traditional models by truly supporting consumers throughout their day and serving as a trusted companion in capacities that are still being imagined. Our results show that the contextual factor is a factor through other consumption values to influence consumers' intentions of mobile Apps use. Thus, developers should consider the element of usage context into the mobile App design.

Second, effective marketing strategies require good knowledge about the needs and value perceptions of consumers. Our results lend support to intuition that emotional and epistemic value play important roles in mobile Apps use. The qualities of fun and pleasure are the most important to consumers. Nevertheless, entirely new experiences certainly provide epistemic value (Sheth et al., 1991a), but as familiarity with Apps grows, the epistemic value might gradually decline, and value assessment criteria might change across these scenarios and this needs evaluation. Therefore, practitioners besides enrich the functions of Apps, also need to keep Apps eye-catching and fascinatingly appealing to stimulate consumers increasing and intense epistemic curiosity to use Apps.

\section{Limitation and Suggestions}

This study arises from the use of a survey method to collect data. Since the sample data is only collected from Taiwan, this may have introduced a bias. For future research, cross-national research is encouraged to investigate whether different cultures may have different value structures and different behavior patterns.

\section{References}

Ajzen, I. (1991). The theory of planned behavior. Organizational behavior and human decision processes, 50(2), 179-211. http://dx.doi.org/10.1016/0749-5978(91)90020-T

Anderson, J. C., \& Gerbing, D. W. (1988). Structural equation modeling in practice: A review and recommended two-step approach. Psychological bulletin, 103(3), 411. http://dx.doi.org/10.1037/0033-2909.103.3.411

Babin, B. J., Darden, W. R., \& Griffin, M. (1994). Work and/or fun: measuring hedonic and utilitarian shopping value. The Journal of Consumer Research, 20(4), 644-656. http://dx.doi.org/10.1086/209376

Bagozzi, R. P., \& Yi, Y. (1988). On the evaluation of structural equation models. Journal of the Academy of Marketing Science, 16(1), 74-94. http://dx.doi.org/10.1007/BF02723327

Balasubramanian, S., Peterson, R. A., \& Jarvenpaa, S. L. (2002). Exploring the implications of m-commerce for markets and marketing. Journal of the Academy of Marketing Science, 30(4), 348-361. http://dx.doi.org/10.1177/009207002236910

Blechar, J., Constantiou, I. D., \& Damsgaard, J. (2006). Exploring the influence of reference situations and reference pricing on mobile service user behaviour. European Journal of Information Systems, 15(3), 285-291. http://dx.doi.org/10.1057/palgrave.ejis.3000618

Braiterman, J., \& Savio, N. (2007). Design sketch: the context of mobile interaction. International Journal of Mobile Marketing, 2(1), 66-68.

Bruner, G. C. (2005). Explaining consumer acceptance of handheld Internet devices. Journal of Business Research, 58(5), 553-558. http://dx.doi.org/10.1016/j.jbusres.2003.08.002

Chen, Y. C., Shang, R. A., \& Lin, A. K. (2009). The intention to download music files in a P2P environment: Consumption value, fashion, and ethical decision perspectives. Electronic Commerce Research and Applications, 7(4), 411-422. http://dx.doi.org/10.1016/j.elerap.2008.02.001

Cheng, J. M. S., Wang, E. S. T., Lin, J. Y. C., \& Vivek, S. D. (2009). Why do customers utilize the internet as a retailing platform?: A view from consumer perceived value. Asia Pacific Journal of Marketing and Logistics, 21(1), 144-160. http://dx.doi.org/10.1108/13555850910926290

Chin, W. W. (1998). The partial least squares approach for structural equation modeling. In G. A. Marcoulides (Ed.), Modern Methods for Business Research (pp. 295-304). Hillsdale, NJ: Lawrence Erlbaum Associates.

Chin, W. W., \& Newsted, P. R. (1999). Structural equation modeling analysis with small samples using partial least squares. Statistical strategies for small sample research, 2, 307-342. 
Davis, F. D., Bagozzi, R. P., \& Warshaw, P. R. (1989). User acceptance of computer technology: a comparison of two theoretical models. Management science, 35(8), 982-1003. http://dx.doi.org/10.1287/mnsc.35.8.982

Deng, Z., Lu, Y., Wei, K. K., \& Zhang, J. (2010). Understanding customer satisfaction and loyalty: An empirical study of mobile instant messages in China. International Journal of Information Management, 30(4), 289-300. http://dx.doi.org/10.1016/j.ijinfomgt.2009.10.001

Eggert, A., \& Ulaga, W. (2002). Customer perceived value: a substitute for satisfaction in business markets? $\begin{array}{lllll}\text { Journal of Business \& Industrial } & \text { Marketing, } & \text { 17(2/3), } & \text { 107-118. }\end{array}$ http://dx.doi.org/10.1108/08858620210419754

Fishbein, M., \& Ajzen, I. (1975). Belief, attitude, intention and behaviour: An introduction to theory and research. Addison-Wesley.

Fornell, C., \& Larcker, D. F. (1981). Evaluating structural equation models with unobservable variables and measurement error. Journal of Marketing Research, 18(1), 39-50. http://dx.doi.org/10.2307/3151312

Gartner. (2011). Retrieved from http://www.gartner.com/it/page.jsp?id=1529214

Gummerus, J., \& Pihlström, M. (2011). Context and mobile services' value-in-use. Journal of Retailing and Consumer Services, 18(6), 521-533. http://dx.doi.org/10.1016/j.jretconser.2011.07.002

Holbrook, M. B. (1994). The nature of customer value: an anthology of services in the consumption experience. Service Quality: New Directions in Theory and Practice, 21-71. http://dx.doi.org/10.4135/9781452229102.n2

Holbrook, M. B., \& Hirschman, E. C. (1982). The experiential aspects of consumption: Consumer fantasies, feelings, and fun. The Journal of Consumer Research, 9(2), 132-140. http://dx.doi.org/10.1086/208906

Hsu, F. M., \& Chen, T. Y. (2007). Understanding Information Systems Usage Behavior in E-Government: The Role of Context and Perceived Value. Paper presented at the Pacific Asia Conference on Information Systems, 2007.

Hung, S. Y., Ku, C. Y., \& Chang, C. M. (2003). Critical factors of WAP services adoption: an empirical study. Electronic Commerce Research and Applications, 2(1), 42-60. http://dx.doi.org/10.1016/S1567-4223(03)00008-5

Kim, B., \& Han, I. (2009). What drives the adoption of mobile data services\&quest; An approach from a value perspective. Journal of Information Technology, 24(1), 35-45. http://dx.doi.org/10.1057/jit.2008.28

Kim, H. W., Chan, H. C., \& Gupta, S. (2007). Value-based adoption of mobile internet: an empirical investigation. Decision Support Systems, 43(1), 111-126. http://dx.doi.org/10.1016/j.dss.2005.05.009

King, W. R., \& He, J. (2006). A meta-analysis of the technology acceptance model. Information \& Management, 43(6), 740-755. http://dx.doi.org/10.1016/j.im.2006.05.003

Lee, M. C. (2009). Factors influencing the adoption of internet banking: An integration of TAM and TPB with perceived risk and perceived benefit. Electronic Commerce Research and Applications, 8(3), 130-141. http://dx.doi.org/10.1016/j.elerap.2008.11.006

Lee, Y., Kim, J., Lee, I., \& Kim, H. (2002). A cross-cultural study on the value structure of mobile internet usage: comparison between Korea and Japan. Journal of Electronic Commerce Research, 3(4), 227-239.

Mallat, N., Rossi, M., Tuunainen, V. K., \& Oorni, A. (2009). The impact of use context on mobile services acceptance: The case of mobile ticketing. Information \& Management, 46(3), 190-195. http://dx.doi.org/10.1016/j.im.2008.11.008

Monroe, K. B. (1990). Pricing: Making profitable decisions. McGraw-Hill Pub. Co.

Okazaki, S. (2008). Exploring experiential value in online mobile gaming adoption. CyberPsychology \& Behavior, 11(5), 619-622. http://dx.doi.org/10.1089/cpb.2007.0202

Pihlstrom, M., \& Brush, G. J. (2008). Comparing the perceived value of information and entertainment mobile services. Psychology and Marketing, 25(8), 732-755. http://dx.doi.org/10.1002/mar.20236

Pura, M. (2005). Linking Perceived Value and Loyalty in Location-Based Mobile Services. Managing Service Quality, 15(6), 509-538. http://dx.doi.org/10.1108/09604520510634005

Ravald, A., \& Grönroos, C. (1996). The value concept and relationship marketing. European journal of marketing, 30(2), 19-30. http://dx.doi.org/10.1108/03090569610106626 
Rogers, E. M. (1995). Diffusion of innovations. Free Pr.

Sanchez-Fernandez, R., \& Iniesta-Bonillo, M. (2007). The concept of perceived value: a systematic review of the research. Marketing Theory, 7(4), 427-451. http://dx.doi.org/10.1177/1470593107083165

Sheth, J. N., Newman, B. I., \& Gross, B. L. (1991a). Consumption values and market choices: theory and applications. Cincinnati: South-Western Pub.

Sheth, J. N., Newman, B. I., \& Gross, B. L. (1991b). Why we buy what we buy: a theory of consumption values. Journal of Business Research, 22(2), 159-170. http://dx.doi.org/10.1016/0148-2963(91)90050-8

Siegler, M. (2008). Analyst: There's a great future in iPhone apps. Retrieved from $\mathrm{http}: / /$ venturebeat.com/2008/06/11/analyst-theres-a-great-future-in-iphone-apps/

Sweeney, J. C., \& Soutar, G. N. (2001). Consumer perceived value: The development of a multiple item scale. Journal of retailing, 77(2), 203-220. http://dx.doi.org/10.1016/S0022-4359(01)00041-0

Sweeney, J. C., Soutar, G. N., \& Johnson, L. W. (1999). The role of perceived risk in the quality-value relationship: a study in a retail environment. Journal of retailing, 75(1), 77-105. http://dx.doi.org/10.1016/S0022-4359(99)80005-0

Tarn, J. L. M. (1999). The effects of service quality, perceived value and customer satisfaction on behavioral intentions. Journal of Hospitality Marketing \& Management, 6(4), 31-43. http://dx.doi.org/10.1300/J150v06n04_04

TRI. (2010). Retrieved from http://www.topology.com.tw/tri/

Tseng, F. M. (2011). Antecedents of consumers' Intetnions to Upgrade their mobile phones. Telecommunications Policy, 35x, 13. http://dx.doi.org/10.1016/j.telpol.2010.11.003

Turel, O., Serenko, A., \& Bontis, N. (2007). User acceptance of wireless short messaging services: Deconstructing perceived value. Information \& Management, 44(1), 63-73. http://dx.doi.org/10.1016/j.im.2006.10.005

Turel, O., Serenko, A., \& Bontis, N. (2010). User acceptance of hedonic digital artifacts: A theory of consumption values perspective. Information \& Management, 47(1), 53-59. http://dx.doi.org/10.1016/j.im.2009.10.002

Tzeng, J. Y. (2011). Perceived values and prospective users' acceptance of prospective technology: The case of a career eportfolio system. Computers \& Education, 56(1), 157-165. http://dx.doi.org/10.1016/j.compedu.2010.08.010

Verkasalo, H., López-Nicolás, C., Molina-Castillo, F. J., \& Bouwman, H. (2010). Analysis of users and non-users of smartphone applications. Telematics and Informatics, 27(3), 242-255. http://dx.doi.org/10.1016/j.tele.2009.11.001

Wikipedia. (2012). Retrieved from http://en.wikipedia.org/wiki/Mobile_app

Woodruff, R. B. (1997). Customer value: the next source for competitive advantage. Journal of the Academy of Marketing Science, 25(2), 139-153. http://dx.doi.org/10.1007/BF02894350

Yang, K., \& Jolly, L. D. (2009). The effects of consumer perceived value and subjective norm on mobile data service adoption between American and Korean consumers. Journal of Retailing and Consumer services, 16(6), 502-508. http://dx.doi.org/10.1016/j.jretconser.2009.08.005 


\section{Appendix A.}

\begin{tabular}{|c|c|}
\hline Construct & Items \\
\hline $\begin{array}{l}\text { Functional value } \\
\text { (FV) }\end{array}$ & $\begin{array}{l}\text { 1. Mobile Apps fulfill my needs as well. } \\
\text { 2. Mobile Apps have acceptable standard of quality. } \\
\text { 3. Mobile Apps offers consistent quality. } \\
\text { 4. The price of mobile App is economical. } \\
\text { 5. The mobile App is good for current price level. }\end{array}$ \\
\hline $\begin{array}{l}\text { Social Value } \\
(\mathrm{SV})\end{array}$ & $\begin{array}{l}\text { 1. Using mobile App helps me to feel acceptable by others. } \\
\text { 2. Using mobile App makes a good impression on other people. } \\
\text { 3. Using mobile App gives me social approval. } \\
\text { 4. Using mobile App improves the way I am perceived. }\end{array}$ \\
\hline $\begin{array}{l}\text { Emotional Value } \\
\text { (EMV) }\end{array}$ & $\begin{array}{l}\text { 1. Using mobile App is interesting. } \\
\text { 2. Using mobile App makes me feel good. } \\
\text { 3. Using mobile App give me pleasure. } \\
\text { 4. Using mobile App makes me feel relax. } \\
\text { 5. Using mobile App is an enjoyment. }\end{array}$ \\
\hline $\begin{array}{l}\text { Epistemic Value } \\
(\mathrm{EPV})\end{array}$ & $\begin{array}{l}\text { 1. Mobile Apps enable me to test the new technologies. } \\
\text { 2. Mobile Apps make experiment with new ways of doing things. } \\
\text { 3. Mobile Apps arouse my curiosity. }\end{array}$ \\
\hline $\begin{array}{l}\text { Conditional Value } \\
(\mathrm{CV})\end{array}$ & $\begin{array}{l}\text { 1. When in an unfamiliar environment of get lost, using mobile App can help } \\
\text { me to identify my current location and further direction. } \\
\text { 2. No matter what time or place is, using mobile Apps can assist me complete } \\
\text { those thing that I want to do. } \\
\text { 3. When I am in uncertain circumstances and need more information to } \\
\text { facilitate decision, mobile Apps can provide related real-time information (e.g. } \\
\text { bus arrival time, weather, stocks) to help me make the decision. }\end{array}$ \\
\hline $\begin{array}{l}\text { Behavioral Intention } \\
\text { (BI) }\end{array}$ & $\begin{array}{l}\text { 1. I intend to use mobile Apps in the near time. } \\
\text { 2. I predict that I would use mobile Apps in the short term. } \\
\text { 3. I expect my use of mobile Apps to continue in the future. } \\
\text { 4. I would use mobile Apps without hesitation to satisfy my needs. }\end{array}$ \\
\hline
\end{tabular}

